\title{
Simulation of flameless combustion of diesel oil
}

\author{
Jamil Al Asfar ${ }^{1 *}$, Zayed Hamamre ${ }^{2}$, Rami Owais ${ }^{2}$ \\ ${ }^{1}$ Mechanical Engineering Department, The University of Jordan, Amman 11942, Jordan \\ ${ }^{2}$ Chemical Engineering Department, The University of Jordan, Amman 11942, Jordan
}

Corresponding Author Email: jasfar@ju.edu.jo

https://doi.org/10.18280/ijht.360405

Received: 9 April 2018

Accepted: 3 September 2018

\section{Keywords:}

flameless combustion, liquid diesel oil, adiabatic flame temperature, Ansys/

Fluent software, simulation

\begin{abstract}
In this work, the combustion process of diesel $\left(C_{12} H_{23}\right)$ in an industrial scale burner under flameless expected operating conditions has been modeled and simulated using Ansys/Fluent software. A wide range of affecting parameters has been analyzed to investigate the applicability of utilizing such liquid fuel for the proposed flameless combustion mode. Natural recirculation of the reaction produced flue gases due to the selected velocity difference between the six fresh air inlets, and the central fuel injection nozzle.

This recirculation affected the flame characteristics by diluting the oxidant concentration into the reaction zone to be within 3-9\% instead of $21 \%$. On the other hand, the recirculation cools down flame reaction zone to $1200 \mathrm{~K}$ in order to aid the auto-ignition of the nonpremixed combustion process, whereas fresh air is preheated to $800 \mathrm{~K}$.

Upon achieving flameless combustion conditions numerically in this study, considerable reduction of maximum operating temperature of around $1600 \mathrm{~K}$ has been reached in most cases, with homogeneous temperature profiles of almost no hot spots. Environmentally, flameless mode showed very friendly environment behaviors where $N O_{x}$ formation rate can be considered nil and does not exceed few ppms. Moreover, the combustion process was completed within a compact design since nil concentration of $C O$ was obtained, with stoichiometric concentrations of $\mathrm{CO}_{2}$ and $\mathrm{H}_{2} \mathrm{O}$. The obtained results were compared with previous results of similar theoretical modeling of flameless combustion for similar liquid fuel, where good agreement was found.
\end{abstract}

\section{INTRODUCTION}

Liquid petroleum fuels are one of the most common energy sources worldwide. One of the main concerns regarding such valuable source of energy is how to be completely utilized in efficient way including the environmental effect. So, related researches are focusing on development of a hydrocarbon fuel combustion process to find an efficient and environment-friendly combustion technique. Flameless combustion is one of the recent clean and efficient technique, known as Flameless Oxidation (FLOX), or as Moderate or Intense Low-oxygen Dilution (MILD). The flameless combustion technology is based on the principle of non-premixed (diffusion) combustion, where fuel and oxidizer remain separated prior to combustion. Air is preheated to a very high temperature (exceeding the selfignition temperature of the fuel) while part of the combustion products is circulated into the reaction zone to reduce the final temperature to be lower than the adiabatic flame temperature.

Recirculation of flue gases controls the temperature within the reaction zone and reduces the oxygen concentration. Recirculation process may be natural by controlling the difference between the center injection point and the surrounding velocities in order to generate a vacuum space to mix the recirculated flue gases with the fresh oxidant feed. Furthermore, forced recirculation of flue gas may be achieved by recycling part of the flue gases and purge the rest to achieve the flameless low oxygen concentration as shown in Figure 1. By achieving these conditions, stable and smooth flameless combustion mode is obtained with very low nitrogen oxides emissions. Flameless combustion can be achieved if the oxygen concentration ranges from 3 to $15 \%$ instead of $21 \%$, where the conventional flames take place. Figure 2 shows the flameless combustion mode region [1-2]. Diesel oil is one of the most commonly used hydrocarbons fuels in industry. So, improving the flameless technology to make it applicable to cover such liquid fuel is of high importance.

High cost laboratory experimental work and the more expensive pilot plants forced the scientists to improve a hypothetical lab to design, simulate, and improve processes before building them. So, Computational Fluid Dynamic (CFD) was utilized to find the characteristics of the flameless combustion process of fuels including diesel oil, where a lot of flow, heat transfer, mass transfer, chemical reaction, and other associated phenomena have been simulated. The obtained results were used to find optimum burner nozzle and orientation to achieve flameless combustion process where a homogenous temperature distribution and low pollutant emissions are obtained. Other factors such as Air to fuel ratio, flame velocity, preheating, injection, maximum combustion efficiency and minimum $\mathrm{NO}_{\mathrm{x}}$ formation was also studied.

Derudi and Rota [4] confirmed the applicability of using liquid fuels for the flameless combustion mode, but with slightly different characteristics. A dual nozzle laboratory scale burner was used to investigate the sustainability of the flameless combustion for liquid hydrocarbons. They found 
that flameless combustion characteristics are more influenced by the physical state of the fuel than that by the chain length of the hydrocarbon.

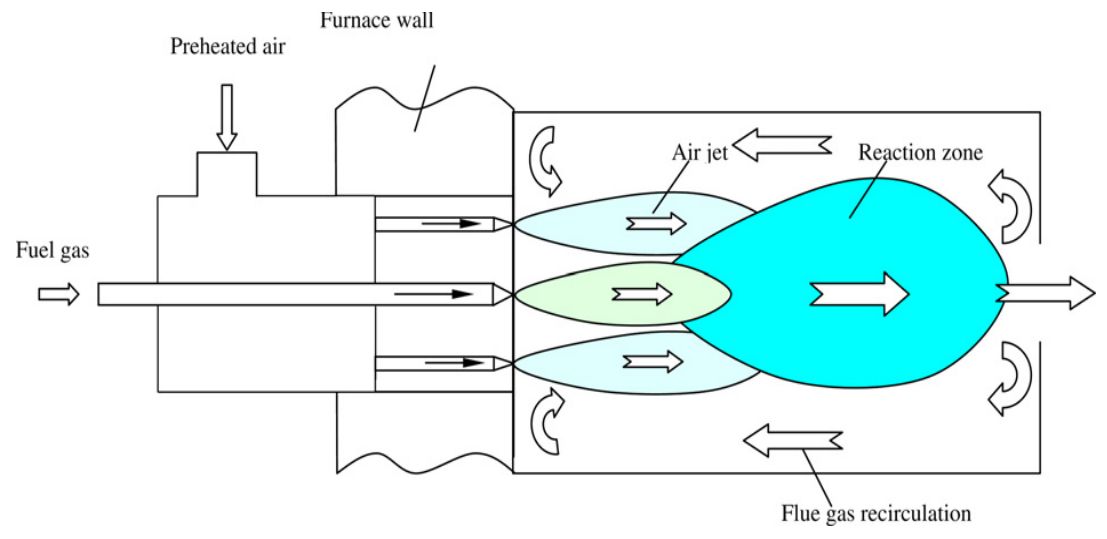

Figure 1. Flameless combustion burner [1]

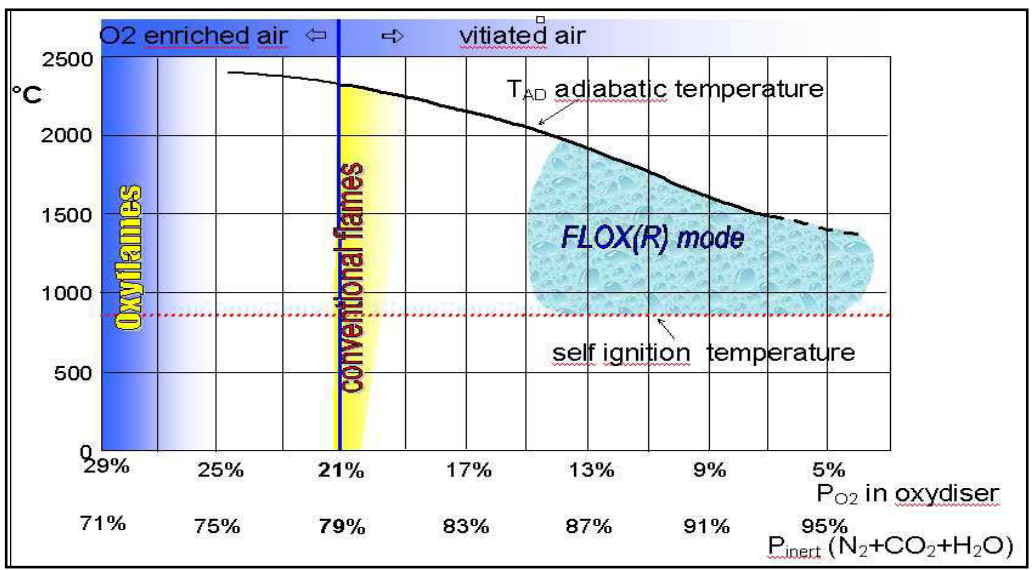

Figure 2. Flameless combustion operable region [2]

Torresi et el. [5] studied liquid fuel of $\mathrm{C}_{16} \mathrm{H}_{29}$ chemical formula preheated aviated air of $673 \mathrm{~K}$ from a secondary burner which contains $12.59 \% \mathrm{O}_{2}, 74.48 \% \mathrm{~N}_{2}, 9.43 \% \mathrm{CO}_{2}$, and $3.5 \% \mathrm{H}_{2} \mathrm{O}$. They utilized the steady incompressible three-dimensional RANS equations discretized using finite volume approach. They confirmed that under a qualitatively point of view, the obtained results of CFD combustion analysis can be considered compatible with the real experimental results where large temperature reduction to $1400 \mathrm{~K}$ was observed.

Camilo et al. [10] performed a numerical study of flameless combustion with mixtures of methane and a subbituminous pulverized coal. The study was performed using the geometry of a laboratory-scale furnace designed to obtain the flameless combustion regime burning of natural gas. They found that it is possible to obtain a stable flameless combustion regime for the analyzed methane/pulverized coal mixtures, with uniform temperature field when methane is replaced by pulverized coal.

Cui and Lin [11, 12] studied flameless combustion of diesel oil and found that flameless combustion takes place under high temperature with low or high oxidant concentration. They also found that air injection speed is an important parameter to lower the whole combustion reaction rate.

Based on above, not all parameters affecting the conditions of flameless combustion were taken into account when carrying out simulation methods. So, in this work, combustion process of liquid diesel fuel under the effect of flameless combustion technique is studied, analyzed, modeled and simulated numerically using Ansys/Fluent software for different air and fuel inlet velocities, air fuel ratio, air and fuel inlet temperature.

\section{MATHEMATICAL MODEL}

Modeling premixed laminar and turbulent combustion is done by solving the governing equations of continuity, momentum, energy and species equations along with turbulent flow equations from the appropriate turbulent model such as $\mathrm{k}-\varepsilon$. In addition, a turbulent chemistry model is required to include the effects of turbulence on the production rate of species in the main species equations such as eddy dissipation concept (EDC) model [6-7].

The transient terms $\left(\frac{\partial y}{\partial t}\right)$ for all the equations must be dropped in these models since the simulations were based on steady state cases. There are many mechanisms that are responsible for ions formation in flames such as electron transfer, ionization by collision, chemi-ionization and excitation energy transfer. In hydrocarbon-air flames, $\mathrm{H}_{3} \mathrm{O}^{+}$ion is produced by the reaction [7]:

$\mathrm{CHO}^{+}+\mathrm{H}_{2} \mathrm{O} \rightarrow \mathrm{CO}+\mathrm{H}_{3} \mathrm{O}^{+}$

while $\mathrm{CHO}^{+}$ion is produced by the following reaction [8]: 
$\mathrm{CH}+\mathrm{O} \rightarrow \mathrm{CHO}^{+}+\mathrm{e}^{-}$

But, $\mathrm{H}_{3} \mathrm{O}^{+}$is consumed by another reaction:

$\mathrm{H}_{3} \mathrm{O}^{+}+\mathrm{e}^{-} \rightarrow \mathrm{H}_{2} \mathrm{O}+\mathrm{H}$

The continuity equation (mass conservation) for a 2-D axisymmetric flow is:

The mass source $\left(\mathrm{S}_{\mathrm{m}}\right)$ in this model is zero.

$\frac{\partial \rho}{\partial t}+\frac{\partial\left(\rho v_{x}\right)}{\partial x}+\frac{\partial\left(\rho v_{r}\right)}{\partial r}+\frac{\rho v_{r}}{r}=S_{m}$

The momentum equations for $2 \mathrm{D}$ axisymmetric are:

$\frac{\partial\left(\rho v_{x}\right)}{\partial t}+\frac{1}{r} \frac{\partial\left(r \rho v_{x} v_{x}\right)}{\partial x}+\frac{1}{r} \frac{\partial\left(r \rho v_{x} v_{r}\right)}{\partial r}=-\frac{\partial p}{\partial x}+$
$\frac{1}{r} \frac{\partial\left[r \mu\left(2 \frac{\partial v_{x}}{\partial x}-\frac{2}{3}(\nabla \cdot \bar{v})\right)\right]}{\partial x}+\frac{1}{r} \frac{\partial\left[r \mu\left(\frac{\partial v_{x}}{\partial r}+\frac{\partial v_{r}}{\partial x}\right)\right]}{\partial r}+F_{x}$

$\frac{\partial\left(\rho v_{r}\right)}{\partial t}+\frac{1}{r} \frac{\partial\left(r \rho v_{x} v_{r}\right)}{\partial x}+\frac{1}{r} \frac{\partial\left(r \rho v_{r} v_{r}\right)}{\partial r}=-\frac{\partial p}{\partial r}+$

$\frac{1}{r} \frac{\partial\left[r \mu\left(2 \frac{\partial v_{r}}{\partial r}-\frac{2}{3}(\nabla \cdot \bar{v})\right)\right]}{\partial r}+\frac{1}{r} \frac{\partial\left[r \mu\left(\frac{\partial v_{x}}{\partial r}+\frac{\partial v_{r}}{\partial x}\right)\right]}{\partial x}-$

$2 \mu \frac{v_{r}}{r^{2}}+\frac{2}{3} \frac{\mu}{r}(\nabla \cdot \bar{v})+\rho \frac{v_{z}{ }^{2}}{r}+F_{r}$

The external body forces $\left(\mathrm{F}_{\mathrm{x}}\right.$ and $\left.\mathrm{F}_{\mathrm{r}}\right)$ equal zero, and the swirl velocity $\left(\mathrm{v}_{\mathrm{z}}\right)$ is also zero, while the term $\nabla . \overline{\mathrm{v}}$ is given by:

$\nabla \cdot \bar{v}=\frac{\partial v_{r}}{\partial r}+\frac{\partial v_{x}}{\partial x}+\frac{v_{r}}{r}$

The energy equation is:

$\frac{\partial(\rho E)}{\partial t}+\nabla \cdot(\vec{v}(\rho E+p))=\nabla \cdot\left(k_{e f f} \nabla T-\sum_{j} h_{j} \overrightarrow{J_{j}}+\right.$

$\left.\left(\overline{\bar{\tau}}_{e f f} \cdot \vec{v}\right)\right)+S_{h}$

The effective thermal conductivity $\left(\mathrm{k}_{\text {eff }}\right)$ is the sum of turbulent thermal conductivity and the normal one $\left(k+k_{t}\right)$. The third term in the equation $\left(\overline{\bar{\tau}}_{\text {eff }} \cdot \vec{v}\right)$ represents the viscous dissipation. $\overrightarrow{J_{j}}$ represents the diffusion flux of species j. The $S_{h}$ term includes the heat of chemical reactions. For a complete set of equations regarding enthalpy, diffusion, ions, species, NO formation, mixture density, thermal conductivity, viscosity and $\mathbf{k}-\epsilon$ model of turbulence, please refer to Ansys/Fluent user's guide [9].

For non-premixed turbulent flameless combustion process, additional conservation equations for mixture fraction and its variance and turbulent flow transport equations are solved. Flameless oxidation means that the fuel and oxidizer mixture should be introduced into the combustion chamber with temperatures that exceed the auto ignition temperature i.e. the fuel/oxidizer cannot get-together before the combustion chamber. So, The Ansys/Fluent non-premixed combustion model is used for modeling the diesel flameless combustion process. Ansys/ Fluent applies the Probability Density Function (PDF) approach for non-premixed combustion modeling to cover the turbulence chemistry interaction averages.

\section{SIMULATION}

Liquid diesel fuel formula was treated theoretically as $\mathrm{C}_{12} \mathrm{H}_{23}$ [3]. Steady state simulation was performed for $\mathrm{C}_{12} \mathrm{H}_{23}$ combustion process manipulating all the operating conditions to achieve best numerical results. Assuming complete combustion process of diesel in the form of $\mathrm{C}_{12} \mathrm{H}_{23}$ :

$\mathrm{C}_{12} \mathrm{H}_{23}+17.75 \mathrm{O}_{2} \rightarrow 12 \mathrm{CO}_{2}+11.5 \mathrm{H}_{2} \mathrm{O}+\sim 2,015 \mathrm{~J}$

Under the assumption that all of the energy produced within the furnace chamber due to combustion is utilizable and assuming that the combustion process is complete and no incomplete combustion process, the furnace assumed to produce $0.625 \mathrm{MW}$ based on burning $310 \mathrm{~mol} / \mathrm{hr}$ of $\mathrm{C}_{12} \mathrm{H}_{23}$ with required volume of air.

The geometry started from changing the dimension considered within a 2-dimesional liquid fuel combustion tutorial by Fluent. Three dimensional geometry were decided to be studied to avoid the mismatch between the nozzles distribution and the projections considered by the software in the 2-dimensional setting. More accurate presentation for the data and the results is obtained by the 3-dimensional modeling, but it is more extensive utilization of the computational requirements. So, Ansys Design Modular capabilities for lines, circuits, and polygons were used in order to draw the required geometry. In addition, the software capabilities for extrude, revolve, sweep, ... etc., were used to convert the basic drawn shapes into full 3-D drawing and corresponding mesh as shown in Figures 3-5.

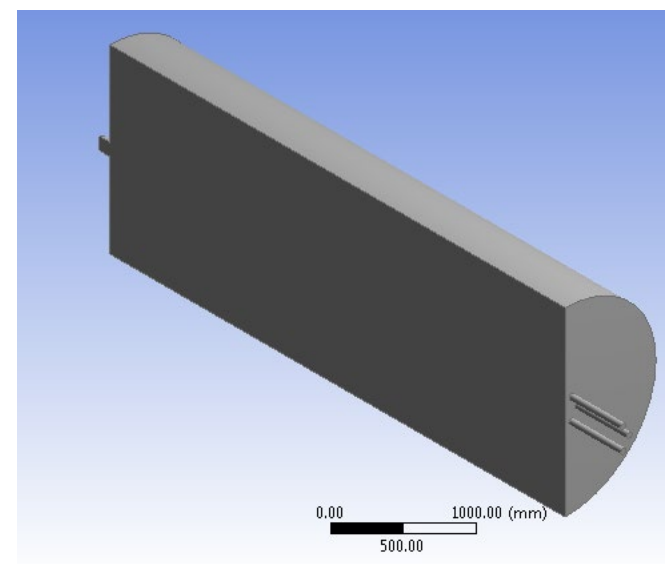

Figure 3. Proposed furnace geometry

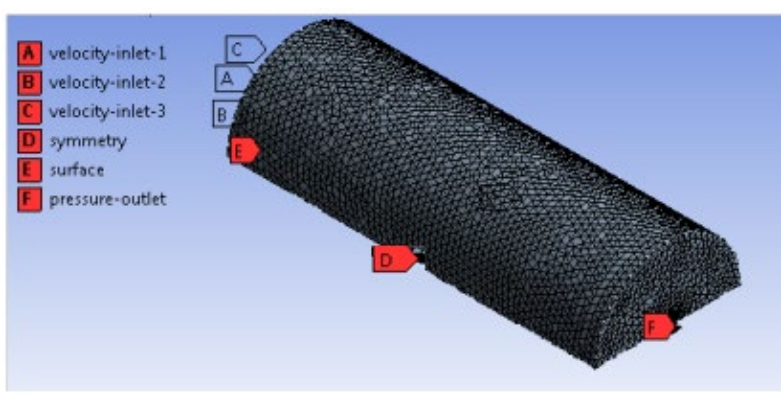

Figure 4. Proposed computation mesh of the furnace 


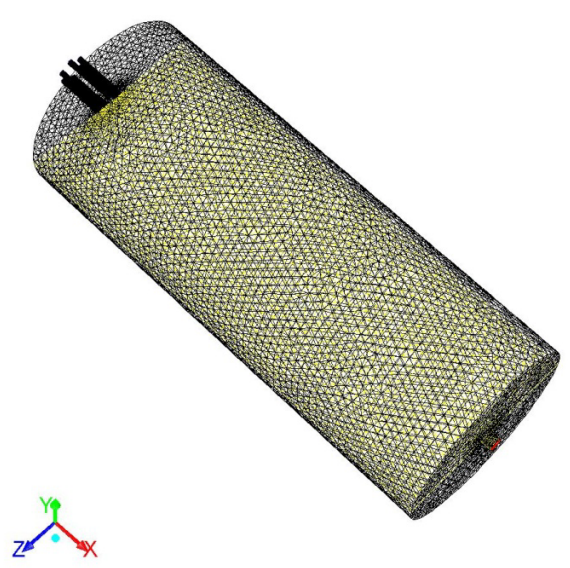

Figure 5. Proposed 3-D furnace for the simulation of the flameless combustion

Three-dimensional furnace geometry $(\phi 1.750 \mathrm{~mm} \times$ $4.500 \mathrm{~mm}$ ) was prepared to suit the simulation of diesel combustion process under flameless operating conditions. The geometry has been auto-meshed into around 158500 tetrahedral cells complete with 307000 triangular faces and 31660 nodes. The Ansys meshing tool was used to mesh the geometry. A grid independent test was performed to ensure that the mesh sizes are considered to produce identical results. The mesh size is refined at the fuel and air inlet to produce the most accurate numerical results. The geometry was made by Ansys Design Modeler [13].

A numerical work was conducted to establish the grid size that produces a grid-independent solution. In the regions near the flame base and flame axis, medium or fine grids are recommended. Furthermore, a fine mesh consisting of 158,424 cells was is satisfactory as the number of iterations per each time step is less than 20 iterations, which is recommended by the software developers. A grid Sensitivity and independent test was performed to ensure that the mesh sizes considered produce identical results of adiabatic flame temperature, as one of the most important parameters in this study.

The predicted temperature distribution using the two schemes: medium and fine meshes indicated that the predicted results of temperature, as critical parameter, satisfied the grid-independent test.

The obtained results were for meshes of 0.52 minimum orthogonal quality and less than $0.11 \%$ of the cells with minimum orthogonal quality of less than 0.63 . Generally, the obtained mesh is fine enough to perform a simulation process for a 3-dimensional geometry to match the available computational capacity.

The average time for the solution to be converged was 18 hours with about 7,500 average number of iterations, which means $8.64 \mathrm{~s}$ per iteration if a commercial laptop of 2.27 $\mathrm{GHz}$ processor. The convergence monitoring tool was the residuals of the solution parameters. The solution convergence monitoring criteria via residuals is shown in Table 1 below.

\section{RESULTS}

Liquid diesel combustion was simulated under the flameless combustion conditions where the fuel-air mixture is above the auto-ignition temperature and the oxygen mole fraction is kept low by natural flue gases recirculation to suite the mentioned flame characteristics. Temperature reduction below the adiabatic is the main indication to confirm the possibility of achieving the flameless combustion mode. There is no real data obtained to confirm the reality of the flame front visibility. These results give expected flame properties and combustion process based on numerical solution of above governing equations. The simulation was carried out using CFD Ansys/Fluent software. Real data could be obtained by building the proposed system and manipulate the operating parameter within the suggested values from this work.

Table 1. Solution convergence monitoring criteria via residuals

\begin{tabular}{|c|c|c|c|c|}
\hline Residual & Model & Default value & Used value & Convergence value \\
\hline Continuity & Flow and DPM & 0.001 & 0.001 & $2.44 \times 10^{-5}$ \\
\hline Velocity & $\begin{array}{c}\text { Flow and } \\
\text { turbulence }\end{array}$ & 0.001 & 0.001 & $9.19 \times 10^{-5}$ \\
\hline Energy & Energy & $1 \times 10^{-6}$ & $5 \times 10^{-5}$ & $1.09 \times 10^{-5}$ \\
\hline$k$ & Turbulence & 0.001 & 0.001 & $1.19 \times 10^{-4}$ \\
\hline Epsilon & Turbulence & 0.001 & 0.001 & $3.13 \times 10^{-4}$ \\
\hline Fmean & $\begin{array}{c}\text { Non-premixed } \\
\text { combustion }\end{array}$ & 0.001 & 0.001 & $7.39 \times 10^{-6}$ \\
\hline Fvar & $\begin{array}{c}\text { Non-premixed } \\
\text { combustion }\end{array}$ & 0.001 & 0.001 & $8.72 \times 10^{-4}$ \\
\hline P1 & Radiation & $1 \times 10^{-6}$ & $1 \times 10^{-5}$ & $7.14 \times 10^{-7}$ \\
\hline Pollutant & $N O_{x}$ & $1 \times 10^{-6}$ & $1 \times 10^{-5}$ & $9.74 \times 10^{-6}$ \\
\hline
\end{tabular}

Results confirm that the flameless combustion is mainly function of the dilution rate and that the flameless region can be achieved if the required conditions make the contact between the fuel and the oxidant at a temperature allowing auto-ignition process. Flameless conditions may also be achieved if there is adequate dilution of the oxidant that would reduce the kinetic of the combustion reaction and reduce the flame front temperature.
The following set of figures represents the results obtained in this study for selected temperature, air inlet velocity and emissions, corresponding to flameless combustion.

The obtained results in this study were compared with previous results of similar theoretical modeling of flameless combustion for similar liquid fuel, but with different molecular formula [5]. Good agreement was obtained. 


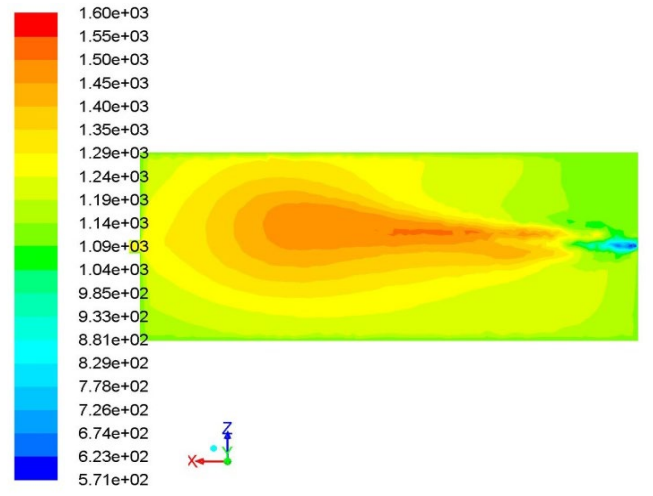

Figure 6. A Temperature profile (K) for stoichiometric combustion conditions

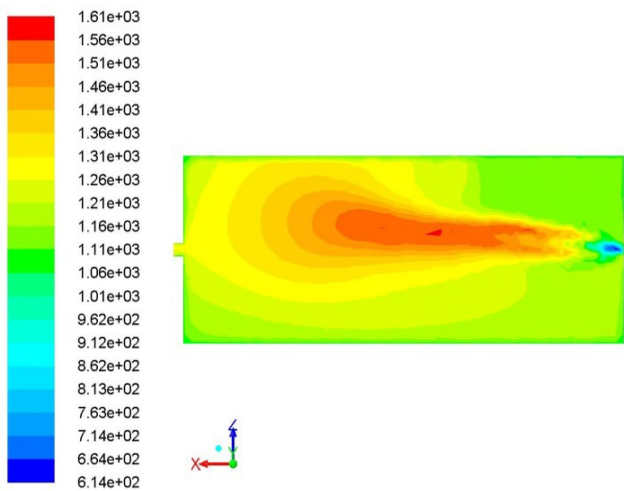

Figure 6. B Temperature profile (K) at $25.1 \mathrm{~m} / \mathrm{s}$ inlet air velocity

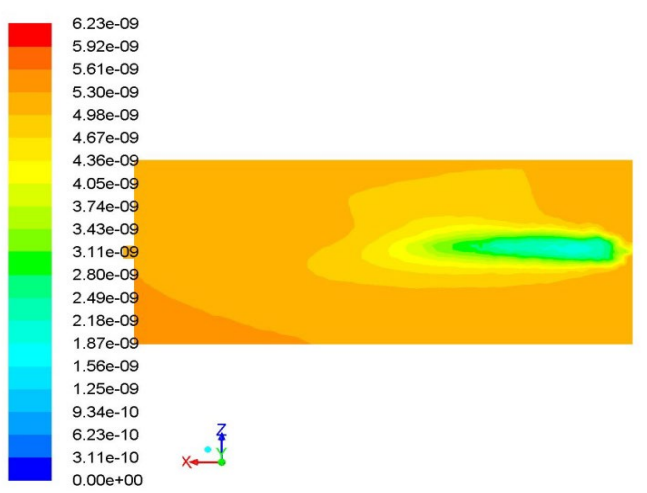

Figure 7. A Mole fraction of pollutant $N O$ for stoichiometric combustion conditions

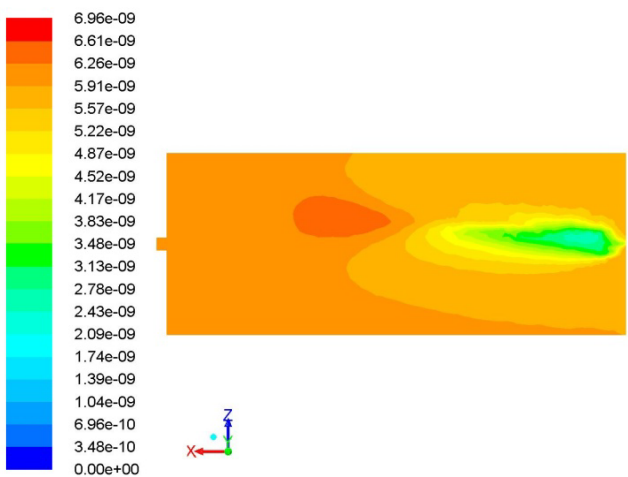

Figure 7. B $N O$ mole fraction profile at $25.1 \mathrm{~m} / \mathrm{s}$ inlet air velocity

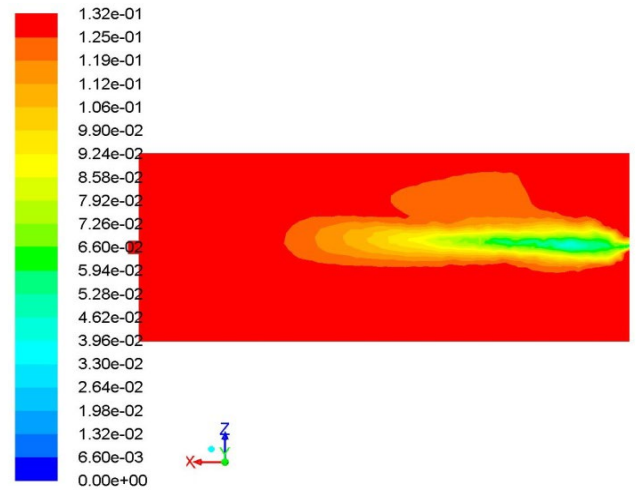

Figure 8. A Mole fraction of $\mathrm{CO}_{2}$ for stoichiometric combustion conditions

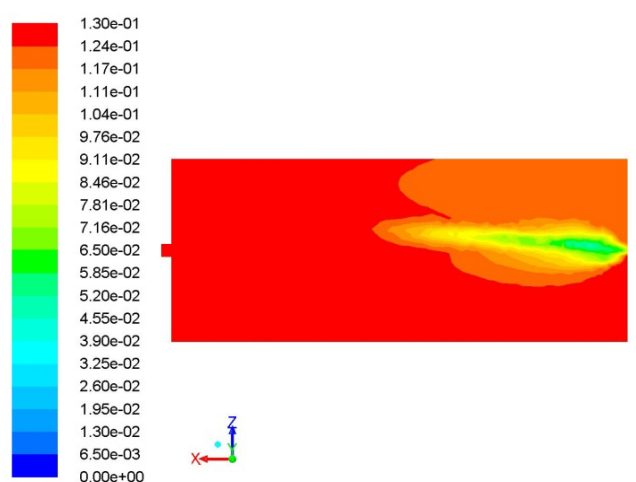

Figure 8. B Mole fraction of $\mathrm{CO}_{2}$ at $25.1 \mathrm{~m} / \mathrm{s}$ inlet air velocity

\section{CONCLUSION}

Flameless combustion has completely different characteristics than the normal flame characteristics. Large reduction of the maximum combustion temperature was achieved under flameless region. While under the conventional combustion conditions, the flame will go to its adiabatic flame temperature. Figures 9A-9B show the temperature difference between the two types of flames using same combustion chamber space and same excess air, but with air preheated to $650 \mathrm{~K}$, and inlet velocity of $1 \mathrm{~m} / \mathrm{s}$ without a driving force for the recirculation of any flue gases.

Combined fresh air with the recirculated flue gases controls the temperature into the reaction zone. Temperature exceeding the auto-ignition temperature should be established and it is recommended to have more than $1000 \mathrm{~K}$ at the beginning of the oxidation region to establish flameless mode.

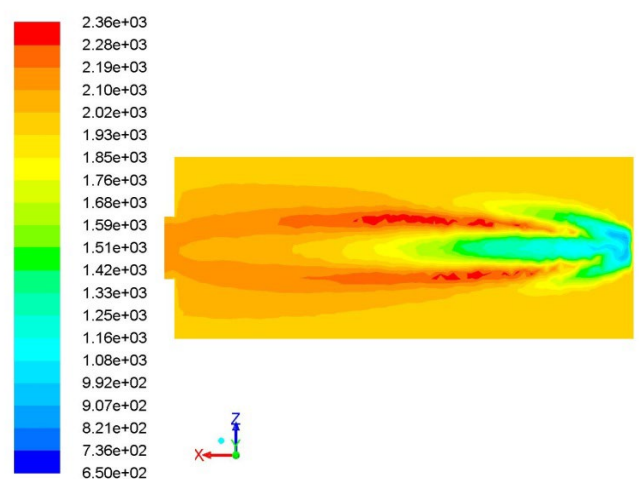

Figure 9. A Conventional flame temperature profile (K) 


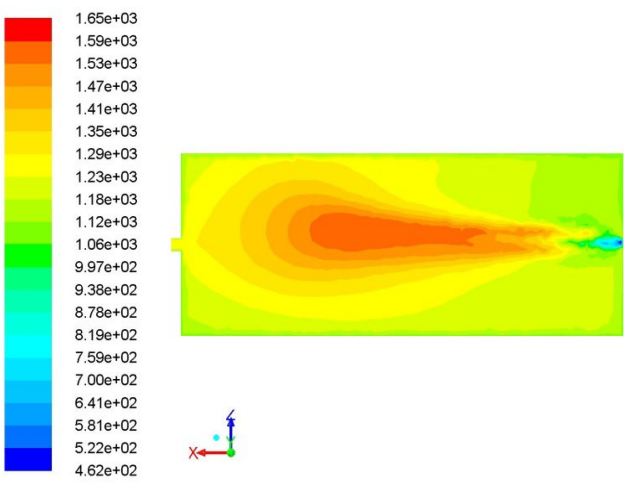

Figure 9. B Flameless combustion expected temperature profile $(\mathrm{K})$

The flameless technology applied utilizing diesel liquid fuel has very attractive characteristics regarding the fuel complete utilization where it has showed a high degree of complete reaction with neglected amount of the harmful $\mathrm{CO}$ side reaction. In addition, very low $N O$ formation rates have been calculated and they are much lower than expected (very close to zero ppm) and comply with any existing environmental regulations. So, Non-premixed combustion technology is of great importance when it is enhanced by the pre-heating of the oxidant and/ or the fuel and entered the combustion chamber at high velocities controlled to establish recirculation of large amount of the inert gases in order to dilute the combustion region in regard to the oxidant concentration which will slow down the reaction but make it complete and clean. Furthermore, it is recommended to preheat both the air and the fuel to pre- evaporation temperature as this will reduce the space of evaporation region. The obtained results were compared with previous results of similar theoretical modeling of flameless combustion for similar liquid fuel, and good agreement was obtained.

\section{REFERENCES}

[1] Wang YD, McIlveen-Wright D, Huang Y, Hewitt N, Eames P, Rezvani S, McMullan J, Roskilly AP. (2007). The application of FLOX/COSTAIR technologies to reduce NOx emissions from coal/biomass fired power plant: A technical assessment based on computational simulation. Fuel (Electronic version) 86: 2101-2108. https://doi.org/10.1016/j.fuel.2007.01.013

[2] Milani A, Saponaro A. (2001). Diluted combustion technologies. IFRF Combustion Journal. Article Number: 200101.
[3] Gupta RB, Demirbas A. (2010). Gasoline, diesel, and ethanol biofuels from grasses and plants. Cambridge University Press. 32 Avenue of the Americas, New York. http://dx.doi.org/10.1017/CBO9780511779152

[4] Derudi M, Rota R. (2010). Experimental study of the mild combustion of liquid hydrocarbons. Proceedings of the Combustion Institute (Electronic Version) 33: 33253332. http://dx.doi.org/10.1016/j.proci.2010.06.120

[5] Torresi M, Camporeale SM, Fortunato B, Ranaldo S, Mincuzzi M, Saponaro A. (2010). Diluted combustion in an aerodynamically staged swirled burner fueled by diesel oil. Processes and Technologies for Sustainable Energy, Ischia. https://doi.org/10.4405/ptse2010.111

[6] Lunder BE, Spalding DB. (1974). The numerical computation of turbulent flows. Computer Methods in Applied Mechanics and Engineering 3: 269-289. http://dx.doi.org/10.1016/0045-7825(74)90029-2

[7] Calcote HF. (1962). Ion production and recombination in flames. Proceeding of the Combustion Institute 8: 184-199. http://dx.doi.org/10.1016/S00820784(06)80502-3

[8] Magnussen BF. (2005). The eddy dissipation concept. A bridge between science and technology. ECCOMAS Thematic Conference on Computational Combustion, Lisbon.

[9] Ansys/Fluent user's guide, release 13.0, Nov. 2010.

[10] Camilo L, Julián O, Andrés A. (2017). Numerical simulation of a flameless combustion furnace with mixtures of methane and a sub-bituminous pulverized coal. Combustion Science and Technology 189(9): 1591-1604. http://dx.doi.org/10.1080/00102202.2017.1305370

[11] Cui YJ, Lin QZ. (2012). Realization of flameless combustion of liquid fuel. Advanced Materials Research 512-515: 2088-2092. http://dx.doi.org/10.4028/www.scientific.net/AMR.512515.2088

[12] Cui YJ, Ye T, Lin QZ. (2012). Effect of fuel air equivalence ratio on the flameless combustion of liquid hydrocarbon. J. of University of Science and Technology of China 42(4): 325-334. http://dx.doi.org/10.3969/j.issn.0253-2778.2012.04.010

[13] Study on combustion characteristics of dimethyl ether (DME) under the moderate or intense low-oxygen dilution (MILD) condition, January 2016. Energy Conversion and Management 108: 549-565. https://doi.org/10.1016/j.enconman.2015.11.039 